\title{
USPPDT (University Student Psychosocial Problems Development Theory)
}

\author{
Norman David Nsereko \\ Nkumba University, Entebbe, Uganda
}

\author{
Seggane Musisi \\ Makerere University, Kampala, Uganda
}

\begin{abstract}
USPPDT (University Student Psychosocial Problems Development Theory) is a psychological model that seeks to explain university students' mental health. The model is an outcome of a Ph.D. study at Nkumba University that developed and validated an instrument to measure university students' psychosocial problems in Uganda. USPPDT is multidimensional suggesting that emotional, academic, antisocial behaviour problems and traumatic experiences, student demographic characteristics, study program characteristics and student related burden characteristics explain and predict psychosocial problems among university students. USPPDT posits that psychosocial vulnerability which has been identified as emotional, academic, antisocial behavior problems and traumatic experiences through a psychometrically sound instrument has a role to play in the understanding of university students' mental health problems.
\end{abstract}

Keywords: theory, psychosocial problems, university students, multidimensional model, mental illness

\section{Background and Orientation}

USPPDT (University Student Psychosocial Problems Development Theory) is a psychological model that seeks to explain university students' mental health with the theoretical reasons the important connections that we think describe most of what is going on in the phenomenon of psychosocial problems among university students. This is done by considering a multidimensional approach to understanding mental illness as suggested by the contendingbiopsychosocial model of mental health that incorporates the social, psychological, and behavioural dimensions of mental illness (Engel, 1977). The model was developed in response to the gaps in understanding university students' mental health problems.

The model is an outcome of a Ph.D. study at Nkumba University that developed and validated an instrument to measure university students' psychosocial problems in Uganda (Nsereko, Musisi, \& Holtzman, 2014). USPPDT provided empirically supported frameworks that explained student psychosocial problems. Emotional, academic, antisocial behavior problems and traumatic experiences, accounted for a high variance explained of $R^{2}=0.74$ (74\%) while students' demographic characteristics, study program characteristics and student related burden characteristics accounted for a variance explained of $R^{2}=0.22(22 \%)$ of psychosocial problems. Psychosocial problems are referred to as those internalizing and externalizing difficulties experienced by an individual student that influence the effective dispositions in mental health.

The model was grounded on an adapted conceptual framework of PSWB (psychosocial well-being)

Norman David Nsereko, Department of Guidance and Counselling, Nkumba University.

Seggane Musisi, Ph.D., professor, senior researcher, Makerere University. 
(Laelia Apicella, Brakarsh, Dube, Jemison et al., 2006). In the model, it was hypothesized that psychosocial problems are influenced by (1) individual factors and experiences (innate personality characteristics, family or household structure, personal exposure to emotional stress and trauma, and socioeconomic status); and (2) contextual factors, e.g., adjustment problems at universities, academic issues, peer influence, relationship issues, economic hardships, new western life styles, e.g., sports gambling/betting, health insecurities, uncertainties in the world of work and the sociopolitical environment. These factors are mutually interconnected.

\section{Discussion}

\section{Gaps in a Multidimensional Approach to Mental Health Illness}

It has been documented that students face multiple protective and risk factors to developing mental health illness (Kneser, 2004; Kitzrow, 2003). They face increasing expectations and demands placed on them by their family members, the university and the changing societal environmental expectations of today and extreme pressure to achieve academically. They also face developmental challenges including increased freedoms, challenging family beliefs, engaging in risky behaviours and concerns regarding sex and HIV/AIDS, as well as dealing with cross-cultural issues, family dysfunctions, alcoholism etc. (Brown-Ogrodnick, 2004; Harper \& Peterson, 2005; Stallman, 2008; Holmes, Silvestri, \& Kostakos, 2011).

A backing factor to this pattern is that situations commonly associated with the onset of mental health problems are habit-forming in the college/university environment (Stallman, 2008; Blanco, Okuda, Wright, Hasin, Grant et al., 2008; Holmes et al., 2011).

A large number of university students may thus be unhappy and emotionally upset but those who manifested major clinical anxiety and depression were only a small percentage which could be clinically determined (Center for Mental Health in Schools at UCLA, 1995). Their true internal pathology through psychiatric assessment, accounted for a relatively small percentage in the overall emotional and psychosocial disturbances which the students faced (Eisenberg, Gollust, Golberstein, \& Hefner, 2007). Indeed, those who might have these major disorders may not necessarily be caused by internal pathology but by other psychosocial factors such as antisocial behaviour (Center for Mental Health in Schools at UCLA, 1995).

A critical review of current literature and research in mental health reveals a number of gaps in understanding university students' mental health and the risk factors to the development of psychosocial problems. University student's mental health problems are constructed within increasingly narrow theoretical, clinical and research frameworks (Mowbray \& Holter, 2002). These emphasize a medical and pathology based construction of student's behavior looking at syndromes such as depression or anxiety (Eisenberg et al., 2007; Ovuga, Boardman, \& Wasserman, 2006) rather than one that takes into account the meaning of student's psychosocial contextual variables (Engel, 1977; Nsereko, Musisi, Nakigudde, \& Holtzman, 2014). These studies have concentrated on unidimensional aspects of these problems and less is known about potential risk factors within young adults, and student populations in particular to constitute psychosocial problems. Others have studied particular aspects to include demographics, e.g., sex, age (Silverman, Meyer, Sloane, Raffel, \& Pratt, 1997); student economic issues (Roberts, Golding, Towell, \& Weinreb, 1999); experiences of sexual victimization (Stepakoff, 1998), depression, anxiety, and suicidality (Ovuga, 2005; Eisenberg et al., 2007); sexual identity or problematic relationships (Kisch, Leino, \& Silverman, 2005); students' academics issues (Svanum \& Zody, 2001; MdYasin \& Dzulkifli, 2009; Atindanbila \& Azasu, 2011); personality traits (Tosevski, Milovancevic, \& Gajic, 2010) indicating that a multidimensional aspect of psychosocial problems is widely 
ignored. These researchers have theoretically suggested a number of psychological, educational, and physiological-related characteristics that were likely to have a relationship with unidimensional psychosocial problems. The risk factors to psychosocial compromised status among university students are therefore not conclusive on available literature (Nsereko, Musisi, Nakigudde, \& Ssekiwu, 2014).

On the other hand, a number of psychosocial theories has been developed and grouped into two main categories namely social cognition models and stage models. These models have been developed to predict, explain, and change health behavior that influences, or is believed to influence, physical health outcomes, either by increasing or decreasing their risk or severity. The social cognition models specify a small number of cognitive and affective factors ("beliefs and attitudes") as the proximal determinants of behavior. For instance, the Health Belief Model (Becker, 1974) sought to explain why some people do not use health services such as immunization and screening. The stage models use similar concepts but organize them in a different way whereby behavior change involves movement through a sequence of discrete, qualitatively distinct, stages. The most commonly used model of this category, TTM (the Transtheoretical Model) includes 15 different theoretical constructs drawn from different theories of behavior change outlining the processes of change in psychotherapy and smoking cessation (Sutton, 2002). The models do not address the hypothesized framework of the presence of psychosocial problems as influenced by individual factors and experiences and contextual factors to explain mental health illness among university students.

\section{Etiology of Mental Health Illness}

Research has indicated that each individual has a degree of vulnerability for the development of mental health problems such as schizophrenia, depression, anxiety, etc.. This can happen due to a combination of biological factors which include, genetics, chemical imbalances in the body or damage to the central nervous system, such as head injury and environmental influences which include exposure to environmental toxins, such as high levels of lead, exposure to violence, such as witnessing or being the victim of physical or sexual abuse, drive-by shootings, muggings, or other disasters; stress related to chronic poverty, discrimination, or other serious hardships; and the loss of important people through death, divorce, or broken relationships (SAMHSA'S National Mental Health Information Center, 2003; Mowbray \& Holter, 2002).

The boundaries between health and disease, between well and sick, are far from clear and never will be clear, for they are diffused by biological, cultural, social, and psychological considerations (Engel, 1977).

Adolescents in particular have been found to suffer from psychosocial problems at one time or the other during their development. Lucas (1976) noted that a group of psychosocial problems than psychiatric illness have been identified to occur to university students at particular times: in relation to entering university, often in relation to study, or examinations or both and in relation to important events in personal and family life. Many of these problems are transitory and are often not noticed. (Ahmad, Khalique, Khan, \& Amir, 2007).

\section{Broader Approach to Mental Health Illness}

The biopsychocial model of mental illness is being proposed today by a new direction for mental health called "critical-psychiatry" as a comprehensive approach to addressing mental health issues in the current mental health debate (Double, 2006). The new contending school of thought suggests an alternative approach to mental illness that incorporates the social, psychological, and behavioural dimensions of mental illness (Engel, 1977).

This approach gives priority to the significance of social, political, and cultural contexts, to the 
interpretation of empirical knowledge and to meaningful psychological experiences for the understanding of mental illness. It argues that mental health practice does not need to be based on an individualistic framework centred on medical diagnosis and treatment (Double, 2006). Particular experiences among different cohorts can be derived to offer specific explanations to mental health vulnerability.

As a hybrid of the different models in approaching mental illness, the biological component would provide the understanding of the somatic component of the illness. The psychological aspects (thoughts, emotions, and behaviours) would offer the psychological causes of the problem by looking at issues like lack of self-control, emotional problems and cognitive influences. The social component would provide the understanding of the social-interpersonal world in which the individual lives by looking at such issues like the social economic status, culture, flaws in parenting, family interactions, stressful situations, or changes in life circumstances, occupation status, etc., that may predispose one to mental illness (Mowbray \& Holter, 2002).

The proponents of the biopsychosocial model also urge that there is a necessity to broaden the understanding and approach to disease by including psychosocial without sacrificing the enormous advantage of the biomedical approach (Engel, 1977). This means that by taking into account the patient, the social context, in which he/she lives, and the complementary system devised by society to deal with the disruptive effects of illness (the physician role, the health care system) will inevitably provide the basis for understanding the determinants of disease and arriving at rational treatments and patterns of health care (Engel, 1977; Double, 2006). Critical psychologists and their followers therefore consider a biopsychosocial model as the ideal in addressing mental health illness.

The theory proposed (see Figure 1) identifies with the growing school of thought that moves away from the unifactorial model for understanding the etiology, course or outcome of mental illness among the student population (Reijneveld, Vogels, Brugman, Van Ede, Verhulst, \& Verloove-Vanhorick, 2003; Zuckerman, 1999; Lucas; 1976, Engel, 1977; Double, 2006) to suggest a broader understanding of a particular multidimensional aspect of psychosocial problems leading to university students' mental health problems. It posits that psychosocial vulnerability which has been identified as emotional, academic, antisocial problems and traumatic experiences through a psychometrically sound instrument and supported by demographic variables has a role to play in the explanation and understanding of university students' mental illness.

\section{Core Assumptions and Statements}

USPPDT is multidimensional suggesting that emotional, academic, antisocial problems and traumatic experiences, student demographic characteristics, study program characteristics and student related burden characteristics explain and predict psychosocial problems among university students. As long as the items underlying a given factor are perceived by an individual as significant they are assumed to lead to a high probability of a compromised psychosocial status. All factors considered together are commonly assumed to predict the likelihood of psychosocial problems and each factor can individually lead to psychosocial problems. All the factors have strong correlations among themselves. Emotional problems represent the internalizing aspect of psychosocial problems with internal dispositions like lack of sleep or sleeping too much, stress, anger, and fear. The academic problems constitute those difficulties that impede academic performance and sustainability. These include motivational factors to study, study outcomes, classroom related behaviours and examination issues. The antisocial behaviour include any behavior being verbal or non-verbal that is not accepted by society and often causes personal harm and to others or may offend others or may destroy property. 
Antisocial behaviour may be gang related behaviours, all types of abuse any behavior an individual would be ashamed of. Traumatic experiences represent threats possessed to an individual and are stressful and may include exposure to family problems, lack of financial support and all adjustment problems at the university, failed relationships, etc.. The student demographic characteristics include age, the study program characteristics include study program, income level of the parents to support the student and living in off campus dormitories, and student related burden characteristics include perception of health, having a previous mental health problem and having a chronic health condition.

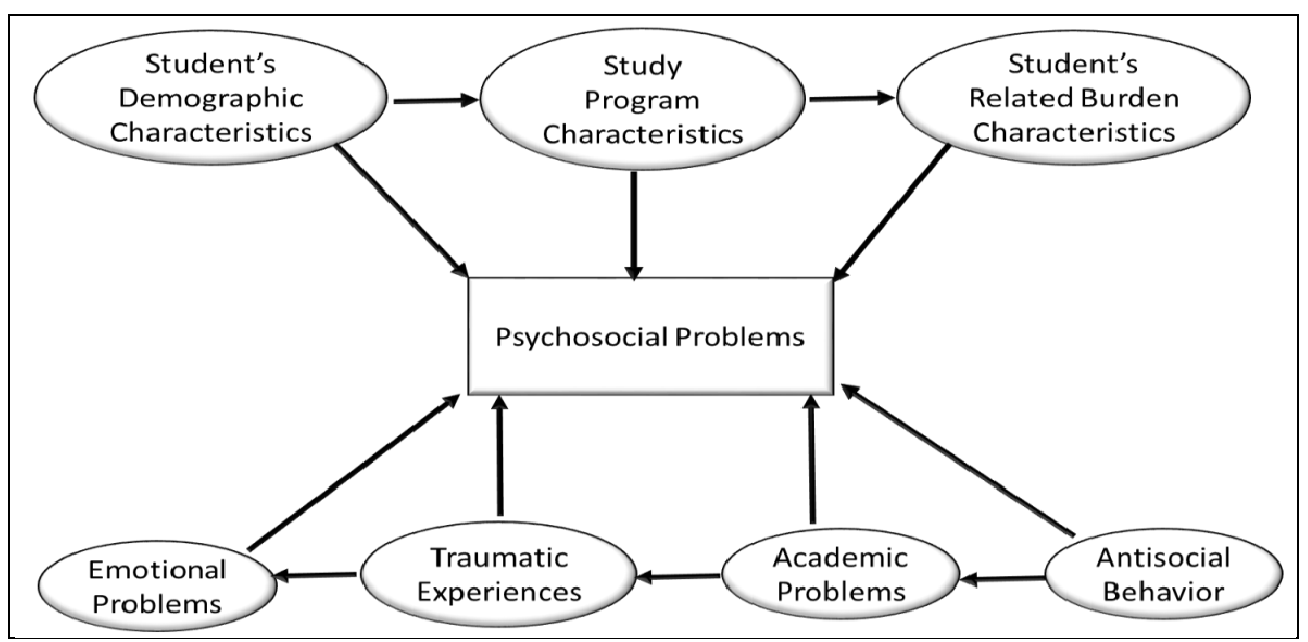

Figure 1. USPPDT (University Student Psychosocial Problems Development Theory).

\section{Conclusion}

The USPPDT has demonstrated that it can explain and predict psychosocial problems of university students in a developing world. It can be used in conjunction with USEPP scales for assessment of clients with psychosocial problems and for research purposes.

\section{References}

Ahmad, A., Khalique, N., Khan, Z., \& Amir, A. (2007). Prevalence of psychosocial problems among school going male adolescents. Indian Journal of Community Medicine, 32, 219-221.

Atindanbila, S., \& Azasu, E. (2011). The types and occurrence of psychosocial problems of distance education (DE) students: A study of a university in Ghana. Journal of Business Research, $5(1$ \& 2), 38-49.

Barrios, L. C., Everett, S. A., Simon, T. R., \& Brener, N. D. (2000). Suicide ideation among U.S. college students. Associations with other injury risk behaviors. Journal of American College Health, 48, 229-233.

Becker, M. H. (1974). The health belief model and personal health behavior. Thorofare, New Jersey: Slack.

Blanco, C., Okuda, M., Wright, C., Hasin, D. S., Grant, B. F., Liu, S., \& Olfson, M. (2008). Mental health of college students and their non-college-attending peers: Results from the national epidemiologic study on alcohol and related conditions. Archives of General Psychiatry, 65, 1429-1437.

Brown-Ogrodnick, A. D. (2004). Factors that influence health services utilization for emotional or mental health reasons among university students (Unpublished masters thesis, University of Saskatchewan, Saskatoon).

Center for Mental Health in Schools at the University of California at Los Angeles (UCLA). (1995). School Mental Health Project at UCLA. Retrieved June 23, 2011, from smhp.psych.ucla.edu

Double, D. B. (2006). Paradigm shift in psychiatry: Processes and outcomes. Retrieved March 21, 2012, from http://www.critpsynet.freeuk.com/paradigm.htm

Eisenberg, D., Gollust, S. E., Golberstein, E., \& Hefner, J. L. (2007). Prevalence and correlates of depression, anxiety, and suicidality among university students. American Journal of Orthopsychiatry, 77(4), 534-542. 
Engel, L. G. (1977). The need for a new medical model: A challenge for biomedicine. Science, New Series, 196(4286), $129-136$.

Harper, R., \& Peterson, M. (2005). Mental health issues and college students. NACADA Clearinghouse of Academic Advising Resources. Retrieved January 10, 2011, from http:/www.nacada.ksu.edu/clearinghouse/advisingissues/mental-health.htm

Holmes, A., Silvestri, R., \& Kostakos, M. (2011). The impact of mental health problems in the community college student population. Toronto: Higher Education Quality Council of Ontario.

Kitzrow, M. A. (2003). The mental health needs of today's college students: Challenges and recommendations. Retrieved June 20 , 2012, from depts.washington.edu/apac/roundtable/1-23-07_mental_health_needs.pdf

Kneser, G. (2004, April). College students leading hyper-enriched lives. Retrieved March 20, 2011, from http://www.stolaf.edu/ president/enewsletter/0404.html\#2

Laelia, G., Apicella, L., Brakarsh, J., Dube, L., Jemison, K., Kluckow, M., Smith, T., \& Snider, L. (2006). Orphans and vulnerable youth in Bulawayo, Zimbabwe: An exploratory study of psychosocial well-being and psychosocial support. Retrieved June 18, 2012, from www.popcouncil.org/pdfs/horizons/zimorphans.pdf

Lucas, C. J. (1976). Aspects of student health psychological problems of students. British Medical Journal, 2, 1431-1433.

Md Yasin, A. S., \& Dzulkifli, M. A. (2009). Differences in psychological problems between low and high achieving students. The Journal of Behavioral Science, 4(1), 49-58.

Mikolajczyk, R. T., Brzoska, P., Maier, C., Ottova, V., Meier, S., Dudziak, U., Ilieva, S., \& El Ansari, W. (2008). Factors associated with self-rated health status in university students: A cross-sectional study in three European countries. Public Health, 8, 215-225.

Mowbray, C. T., \& Holter, M. C. (2002). Mental health and mental illness: Out of the closet? Social Science Review, 76(1), 135-179.

Nsereko, N., Musisi, S., \& Holtzman, S. (2014). Evaluation of psychosocial problems among African university students in Uganda: Development and validation of a screening instrument. Psychology Research, 2(4).

Nsereko, D. N., Musisi, S., Nakigudde, J., \& Holtzman, S. (2014). Prevalence, types, distribution and associations of psychosocial problems among university students in Uganda. International Journal of Research Studies in Psychology, Available online March 17, 2014.

Nsereko, D. N., Musisi, S., Nakigudde, J., \& Ssekiwu, D. (2014). Psychosocial problems and development of psychopathology among Ugandan university students. International Journal of Research Studies in Psychology, Available online February 23, 2014.

Ovuga, E., Boardman, J., \& Wasserman, D. (2006). Undergraduate student mental health at Makerere University, Uganda. World Psychiatry, 5(1), 51-52.

Reijneveld, S. A., Vogels, A. G .C., Brugman, E., Van Ede, J., Verhulst, F. C., \& Verloove-Vanhorick, S. P. (2003). Early detection of psychosocial problems in adolescent: How useful is the Dutch short indicative questionnaire (KIVPA)? European Journal of Public Health, 13, 152-159.

Roberts, R., Golding, J., Towell, T., \& Weinreb, I. (1999). The effects of economic circumstances on British students' mental and physical health. Journal of American College Health, 48, 103-110.

SAMHSA'S National Mental Health Information Center. (2003). Selected mental health publications. Retrieved June 30, 2013, from http://www.idexter.com/understanding/depression/samhsa/8_samhsa_publications.pdf

Silverman, M. M., Meyer, P. M., Sloane, F., Raffel, M., \& Pratt, D. M. (1997). The big ten student suicide study: A 10-year study of suicides on Midwestern University campuses. Suicide Life Threatening Behaviour, 27, 285-303.

Stallman, H. M. (2008). Prevalence of psychological distress in university students: Implications for service delivery. Australian Family Physician, 3(8), 673-677.

Stepakoff, S. (1998). Effects of sexual victimization on suicidal ideation and behavior in U.S. college women. Suicide Life Threatening Behaviour, 28, 107-126.

Sutton, S. (2002). Health behavior: Psychosocial theories. Retrieved March 11, 2013, from userpage.fu-berlin.de/ schuez/folien/ Sutton.pdf

Svanum, S., \& Zody, Z. (2001). Psychopathology and college grades. Journal of Counselling Psychology, 48, 72-76.

Tosevski, D. L., Milovancevic, M. P., \& Gajic, S. D. (2010). Personality and psychopathology of university students. Current Opinion in Psychiatry, 23, 48-52.

Zuckerman, M. (1999). Vulnerability to psychopathology: A biosocial model. Washington, D.C.: American Psychological Association. 